\title{
The effects of accelerating the school curriculum on student outcomes
}

Citation for published version (APA):

Korthals, R. (2017). The effects of accelerating the school curriculum on student outcomes. Maastricht University, Graduate School of Business and Economics. GSBE Research Memoranda No. 003 https://doi.org/10.26481/umagsb.2017003

Document status and date:

Published: 01/01/2017

DOI:

10.26481/umagsb.2017003

Document Version:

Publisher's PDF, also known as Version of record

\section{Please check the document version of this publication:}

- A submitted manuscript is the version of the article upon submission and before peer-review. There can be important differences between the submitted version and the official published version of record.

People interested in the research are advised to contact the author for the final version of the publication, or visit the DOI to the publisher's website.

- The final author version and the galley proof are versions of the publication after peer review.

- The final published version features the final layout of the paper including the volume, issue and page numbers.

Link to publication

\footnotetext{
General rights rights.

- You may freely distribute the URL identifying the publication in the public portal. please follow below link for the End User Agreement:

www.umlib.nl/taverne-license

Take down policy

If you believe that this document breaches copyright please contact us at:

repository@maastrichtuniversity.nl

providing details and we will investigate your claim.
}

Copyright and moral rights for the publications made accessible in the public portal are retained by the authors and/or other copyright owners and it is a condition of accessing publications that users recognise and abide by the legal requirements associated with these

- Users may download and print one copy of any publication from the public portal for the purpose of private study or research.

- You may not further distribute the material or use it for any profit-making activity or commercial gain

If the publication is distributed under the terms of Article $25 \mathrm{fa}$ of the Dutch Copyright Act, indicated by the "Taverne" license above, 


\section{Maastricht University}

Roxanne Korthals

The effects of accelerating the school curriculum on student outcomes

RM/17/003

\section{GSBE}

Maastricht University School of Business and Economics

Graduate School of Business and Economics

P.O Box 616

NL-6200 MD Maastricht

The Netherlands 


\title{
The effects of accelerating the school curriculum on student outcomes
}

Roxanne Korthals

Maastricht University and CIDER

\begin{abstract}
The aim of this paper is to estimate the causal effects of an accelerated curriculum, in which students progress through the course material faster, on cognitive and non-cognitive outcomes. I employ two methods: First, I make use of the cohorts before and after the introduction of the possibility to accelerate and of classes which are and which are not considered for acceleration using a Difference-in-Differences (DiD) strategy. However, it seems reasonable that the best students benefit from this policy, while it is less clear that the less able students would benefit. Therefore I also employ a second method in which I only look at the effects for the marginal student. For this, I use school grades to employ a fuzzy Regression Discontinuity Design (fRDD). Using both methods, I find that after one year the students who accelerated scored significantly higher on certain sub scores of the mathematics tests. I find no definitive results on non-cognitive skills: Using the DiD, I find that this positive cognitive effect is countered by lower scores on the teacher rated scores on perseverance, concentration, and conversation skills. For the marginal student, I find almost no effects on non-cognitive skills.
\end{abstract}

JEL-codes: I20, I21

Keywords: curriculum, instruction hours, student performance, non-cognitive skills 


\section{Introduction ${ }^{1}$}

When high ability students in tracked education systems have preferences for hands-on education, there are faced with a trade-off: Does the student go to the high ability track that provides only general education, or does the student go to the vocational track and face a less stimulating curriculum and possibly less post-secondary options?

In this paper I evaluate the possibility for high ability vocational students within a secondary school in the Netherlands to accelerate the mathematics and/or Dutch language curriculum. When students accelerate the curriculum, they progress through the course material faster. There is no difference in the curriculum itself, in the teaching materials, or in the weekly hours taught for those who accelerate and those who do not. This policy to accelerate provides the high ability students with a hands-on vocational education without a loss in cognitive stimulation and with the possibility to get a head start on post-secondary education in the freed up time.

The aim of this paper is to estimate the causal effects of an accelerated curriculum on cognitive and non-cognitive outcomes. For this I employ two methods: First, I make use of the cohorts before and after the introduction of the possibility to accelerate and of classes that are and which are not considered for acceleration using a Difference-in-Differences (DiD) strategy. However, while the top students are likely to benefit from acceleration, it is less clear whether the less able students would benefit. For this reason, I use a second methodology which looks at the marginal students only: a fuzzy Regression Discontinuity Design (fRDD). Furthermore, the DiD estimates do not allow me to differentiate the effects of accelerating the language from accelerating the mathematics curriculum, while with the individual level fRDD this is possible. From the classes that are considered for acceleration, teachers decide on who gets to accelerate based on the school grades of the students. I make use of individual data on these grades and estimate the threshold in the grades for which the possibility to accelerate increases the most. The threshold therefore causes a discontinuity in the probability to accelerate. Unfortunately, the first stage for accelerating the language curriculum is too weak and thus I only consider the effects of accelerating the mathematics curriculum.

\footnotetext{
${ }^{1}$ I would like to thank the school principal and the data team of the school in question for their help in getting me the data and for answering my many questions. I would also like to thank Inge de Wolf for our cooperation and Bart Golsteyn, Carla Haelermans and participants of the Dutch Economists Days 2016 for useful comments which improved the paper.
} 
The results show that after one year the students who accelerated scored significantly higher on certain sub scores on the mathematics tests. Using the DiD, I find that this positive effect is countered by lower scores on the teacher rated scores on perseverance, concentration, and conversation skills. This result points to a possible trade-off for teachers, students, and parents: The students who accelerated will possibly graduate earlier with higher cognitive skills, but with lower non-cognitive skills. I find almost no effects on non-cognitive outcomes for the marginal student.

In the school policy analyzed here the top students are separated from the less able students, although only for one or two courses (mathematics and Dutch) and not for all courses. It therefore captures similar mechanisms as tracking, in which students are separated into distinct educational programs, and ability grouping, in which students are sorted on ability in an informal way. There is little consensus on the effect of tracking on student performance with some finding positive (e.g. Korthals, 2015), insignificant (e.g. Hanushek and Woessmann, 2006), or negative (e.g. Van Elk et al., 2011) effects. Tracking has also been found to affect non-cognitive skills (e.g. Korthals, 2015). Ability grouping is often found to have positive effects on student performance (e.g. Figlio and Page, 2000; Duflo et al., 2011).

This paper also contributes to the recent literature on instruction hours and learning intensity, since those who accelerate the curriculum have after four years had less instruction hours for mathematics and language and thus higher learning intensity. An increase in instruction hours is found to increase performance (e.g. Borghans and Diris, 2014; Cortes et al., 2015; Rivkin and Schiman, 2015; Lavy 2015) and a higher learning intensity leads to worse outcomes (e.g. Heubener and Marcus, 2015). This seems to be the opposite of the positive effects of acceleration on performance found here. However, the policy looked at in this paper only targeted the high ability students. For them the previous learning intensity might have been too low to begin with. Higher learning intensity has also been found to lead to more extraverted and less emotionally stable students (Dahmman and Anger, 2015).

This paper is structured as follows: The next section provides more information on the school and the treatment. Section 3 describes the methods used, while Section 4 discusses the data 
and checks the main assumptions of the two methods. The DiD and the fRDD results are presented in Sections 5 and 6, respectively. Section 7 concludes.

\section{Treatment}

\subsection{The school}

The secondary school for which I have data is a pre-vocational school in the Netherlands. The Dutch secondary education system is characterized by early selection into tracks (at age 12) with six tracks available to students: four pre-vocational tracks ( $\mathrm{vmbo}$ ) and two general education tracks (havo and vwo). The four pre-vocational tracks are vmbo basis, vmbo kader, vmbo gemengd, and vmbo theoretisch: vmbo basis is the most practical track ("hands-on") and the other tracks have an increasing theoretical focus. The vmbo tracks are four years, the havo track is 5 years, and the vwo track is 6 years. Secondary schools decide on track placement based on an elementary school exit test score and a track recommendation of the elementary school teacher of the students.

Within each track students specialize into different fields of study. In pre-vocational schools students specialize in the Health care, Technical, Administration, or Agriculture sectors. The pre-vocational school I for which I have data on only offers the Technical sector to its students. The choice for the Technical sector means that the students learn to work with heavy machinery and train to become, for instance, car mechanics, electricians, plumber, carpenters, or masons. The focus on technical trades has as a consequence that the school contains mostly boys. Of the 554 students in the whole school, only 17 are girls in the schoolyear 2014/2015.

The school is very popular, which can be seen by the fact that also students with top elementary school exit test scores enter the school. Given their exit test scores, some of these students would be eligible for entry into the highest general education track (vwo), which is the only secondary school track which gives direct access to university. These students will therefore have a strong preference for the two characteristics of this school: vocational, or hands-on, learning and a focus on technical trades. 
At the start of the secondary school classes are being formed based on the elementary exit test and each class is allocated to a different track (vmbo basis, kader, or gemengd). For instance, in 2013/2014 there were 8 classes in the first grade of secondary school (grade 7). Table 1 shows that the average elementary exit test score was 28 out of 100 for class $1 \mathrm{~A}$ and 74 out of 100 for class $1 \mathrm{H}^{2}{ }^{2}$ The students with the lowest scores on the elementary exit test are placed in smaller classes than those with higher scores.

--- Table 1 here ---

\subsection{Acceleration of the curriculum}

Since 2013/2014 some selected students are eligible to accelerate the school curriculum for the courses Dutch and/or mathematics. The acceleration of Dutch starts in April of grade 7, while for mathematics the acceleration starts in September of grade 8. There is no difference in the curriculum, in the teaching materials, or in the weekly hours taught for those who accelerate and those who do not. The only difference is that those who accelerate progress through the course material faster and will thus have had less instruction hours upon completion of the curriculum after four years. Per week, both groups get 3 hours of Dutch, 1 hour of Dutch reading, and 3 hours of mathematics in the first year. In the second and third year, there is no longer one hour for Dutch reading.

By accelerating mathematics and/or Dutch the students will be able to test for the accelerated course(s) at the central exit examination one year before they test the other courses (after three years instead of after four years). The gaps in the schedule of the last year of secondary school can then be filled with extracurricular activities or by courses at the post-secondary level which gives the students an advantage when they enter post-secondary school.

The school has decided that all students from the classes with high average elementary school exit scores (with scores equal or greater than 60, see the classes with an asterisk in Table 1) are considered for the accelerated curriculum. However, not all students in these classes are offered the option to accelerate since teachers discuss on an individual basis whether a

\footnotetext{
${ }^{2}$ The score on the elementary exit test originally ranges from 500 to 550 . For this paper the scores are changed into scores out of 100 . The classes with the lowest average test scores have more missing values on the test score than the higher test score classes, presumably because elementary schools do not let their worst performing students take the test. For the classes with the lowest average test scores, these average scores are therefore most probably an overestimation.
} 
student is offered the option to accelerate. Teachers evaluate whether or not the student shows cognitive capacities on the level of the havo track (the lowest academic track) which are deemed necessary for those who will accelerate. Teachers decide whether the student has these cognitive capacities primarily based upon the students' school grades in mathematics and Dutch. The teachers also look at the progress the student has shown over the year, the attitude of the student towards learning, and the support the student receives at home.

Teachers form an advice for each student in the classes considered for acceleration in March of the first year and this advice is communicated to the parents. In April there is an information evening for the parents about the acceleration. If the parents or students do not want to accelerate, the student is not forced. Not all students who are offered the option choose to accelerate. When the parents or the student want the student to accelerate against the advice of the teacher, the parents have to deliver compelling arguments why the teacher was misguided in her/his advice. None of the students from the classes with average scores below 60 are ever allowed to accelerate.

\section{Methodology}

\subsection{Difference-in-Differences}

I first employ a DiD strategy. For the DiD estimates I make use of the fact that I have data for cohorts before and after the policy started and for classes that are and that are not considered for acceleration. The possibility to accelerate was given for the first time to students from the $2013 / 2014$ cohort, from now on called cohort 1 . However, I also have data from the cohort which started in 2012/2013 (cohort 0) and I know which classes would have been considered for acceleration if the possibility was given (namely those classes with an average elementary exit test score of equal or greater than 60). Table 1 shows the average elementary exit test score for the classes of these cohorts. Using this I can estimate the follow model:

$$
y_{i, c}=\rho_{1}+\rho_{2} \text { HIGH.TEST.CLASS } i, c+\rho_{3} \vartheta_{c}+\rho_{4} \text { HIGH.TEST.CLASS } S_{i, c} * \vartheta_{c}+\varepsilon_{i, c}
$$

The outcomes $y_{i, c}$ are different cognitive and non-cognitive outcomes for individual $i$ in cohort $c$. HIGH.TEST. CLASS $i, c$ is the dummy for the classes with elementary exit test scores equal or greater than 60 . The cohort dummy $\left(\vartheta_{c}\right)$ is 1 for the cohort which has the option to 
accelerate (cohort 1) and zero for the pre-policy cohort (cohort 0 ). In equation (1) the reduced form effect of acceleration on the student outcome is captured by $\rho_{4}$, which is determined by the double difference between the outcome of the classes with elementary exit test scores equal or greater than 60 and those with test scores below 60 (difference 1) and for cohort 1 that could and for cohort 0 that could not accelerate (difference 2).

The assumption of parallel trends before the policy between high test classes and non-high test classes will be tested using data from the cohort 2010/2011 (from now on: cohort -2) and the cohort 2011/2012 (from now on: cohort -1). Table 1 shows that in both cohort -2 and cohort -1 one class had an average elementary exit test score of above 60 and therefore this class would have been considered for acceleration if the possibility was given.

Since I estimate a reduced form and not all students in classes which were considered to accelerate actually accelerate, I underestimate the effect of acceleration. The results shown later are therefore a lower bound of the true effect on the students that accelerate.

\subsection{Fuzzy regression discontinuity design}

Since it is less likely that the marginal student benefit from the treatment than the best students, I make use of the available individual data from the students in the two cohorts for whom acceleration was possible (cohorts 1 and 2) and employ a fRDD. In doing so, I exploit the discontinuity in the possibility to accelerate. Furthermore, the fRDD allows me to differentiate between accelerating the language or the mathematics curriculum.

For both mathematics and reading, the school uses the $4^{\text {th }}$ period school grade in mathematics and Dutch to decide on acceleration. I use the grade with the largest discontinuity in the probability to accelerate as the threshold. ${ }^{3}$ For Dutch the threshold is a period 4 grade of above 71 and for mathematics the threshold is 74. Equations (2) and (3) show the models for mathematics:

$$
\begin{aligned}
& \text { ACCEL_M } M_{i, c}=\gamma_{1}+\gamma_{2} I\left(M 4_{t=1, i, c} \geq 74\right)+\gamma_{3} M 4_{t=1, i, c}+\gamma_{4} y_{t=1, i, c}+\gamma_{5} \theta_{c}+\epsilon_{i, c} \\
& y_{t=2, i, c}=\delta_{1}+\delta_{2} A C \widehat{C E L} M_{i, c}+\delta_{3} M 4_{t=1, i, c}+\delta_{4} y_{t=1, i, c}+\delta_{5} \theta_{c}+\varepsilon_{i, c}
\end{aligned}
$$

\footnotetext{
${ }^{3}$ The threshold which is chosen has the highest $\mathrm{F}$ statistic in a regression looking at acceleration and an indicator function for having a period 4 grade of above the threshold.
} 
Equation (2) estimates the first stage in which whether or not students $i$ of cohort $c$ accelerates the mathematics curriculum $\left(A C C E L_{-} M_{i, c}\right)$ is dependent on whether they score above the threshold for their $4^{\text {th }}$ period mathematics grade in year $1\left(M 4_{t=1, i, c} \geq 74\right)$. Equation (3) shows the second stage where the outcome of student $i$ of cohort $c$ in year 2 $\left(y_{t=2, i, c}\right)$ is determined by the fitted values from the first stage $\left(A \widehat{C C E} L_{i, c}\right)$, the forcing variable $\left(M 4_{t=1, i, c}\right)$, a score on a similar test but before acceleration took place $\left(y_{t=1, i, c}\right)$, and a cohort dummy $\left(\theta_{c}\right)$. Similar equations are used to estimate the effect of acceleration of the language curriculum on the outcomes. Following Lee and Lemieux (2010), I do not restrict the sample to those within a small bandwidth around the cutoff to obtain more precision given my limited sample.

\section{Data}

For the analyses I use administrative individual level data for three cohorts: For the DiD analyses I use data from cohorts 0 and 1; for the fRDD analyses I use data from cohorts 1 and 2.

\subsection{Background information}

For all three cohorts I have limited background data from the school administration: birth date transformed into relative age, the elementary exit test score, and the elementary school teacher recommendation. ${ }^{4}$ Table 2 shows these background characteristics for the three cohorts. The asterisks in Table 2 show whether there is a significant difference for the listed variables between cohort 0 and cohort 1 , and between cohort 1 and cohort 2: The background characteristics do not differ between the three cohorts.

--- Table 2 here ---

Second, I have teacher rated non-cognitive scores collected in February of the first year (grade 7), shown in Table 2. The non-cognitive scores are on communication, a averaged score of presenting yourself, conversation skills, and asking questions, and cooperation, a averaged score of active listening, keeping appointments, and teamwork. Appendix A gives

\footnotetext{
${ }^{4}$ I also have gender. However, since I only have 13 women in my data I exclude them from the analyses.
} 
more information on the precise phrasing of the competencies. The students are scored on a 5-point Likert scale from very bad to excellent. ${ }^{5}$ Teachers of different subjects score the students on some, but not all, items. For instance, the geography teacher rates students in keeping appointments and in conversation skills, while the English teacher rates students on active listening and presenting yourself. All the scores on the different items of different teachers are averaged which results in a single score for each skill.

Finally, I have a number of scores on national tests in the first month of the start of secondary school. These tests are Dutch language, consisting of sub tests in Dutch reading and Dutch vocabulary, general language skills, consisting of grammar and (verbal and non-verbal) spelling, and mathematics, consisting of sub tests in geometry, relationships, numbers, and proportions. The only difference in the pre-acceleration cognitive and non-cognitive skills between cohorts is that students from cohort 0 differ from students from cohort 1 on keeping appointments and the cooperation averaged score (see Table 2).

I estimate models with and without controlling for the pre-acceleration teacher rated noncognitive scores and the pre-acceleration scores on the national tests. The panel dimension of the data allows me to remove possible residual endogeneity.

\subsection{Outcomes}

Table 2 also shows the cognitive and non-cognitive outcomes, which are measured in grade 8 (second syear of secondary school). As cognitive outcomes I have the national tests taken in March of the second year (i.e. 7 to 10 school months after acceleration starts) for which the topics correspond one-to-one to the national tests of the first year. The non-cognitive outcomes are competency scores collected in February of the second year. These competency scores in grade 8 are set up the same as those in grade 7. However, while the grade 7 competencies are communication and cooperation, students in grade 8 are additionally also scored on attitude, a averaged score of independence, perseverance, and concentration.

Table 2 shows little difference between the cohorts in average outcome variables. The only real difference is that the teacher rated non-cognitive scores differ between cohort 1 and cohort 2: For example, cohort 2 has lower attitude scores than cohort 1 . This can be explained

\footnotetext{
${ }^{5}$ Teachers in grade 8 of cohort 2 rated students on a 10-point scale. I transform these score into 5-point scales.
} 
by a change in administering the non-cognitive skills: The teachers who filled in each skill changed slightly and the teachers were asked to use a 10-point scale instead of a five point scale. In the analyses this difference between cohort 1 and 2 is captured by the cohort fixed effects.

\subsection{Parallel trend assumption (DiD)}

The DiD methodology assumes that the high test classes in cohort 1 for which acceleration was possible would have followed the same trend as the high test classes in cohort 0 if acceleration would not have been possible. Whether this assumption holds cannot be tested since this counterfactual did not happen. However, by looking at pre-acceleration trend data, it is possible to get a good idea whether this assumption is reasonable. Figure 1 shows for a selection of cognitive skills the pre- and post-trends for the high test classes and the non-high test classes over time.

--- Figure 1 here ---

For most outcome variables the parallel trend assumption seems quite reasonable (for the overall mathematics score, geometry, proportions, connections, Dutch non-verb spelling, grammar, Dutch vocabulary, Dutch reading), while for a few it seems not to hold (for numbers, General language skills, non-verb spelling). I will take these pre-trends into account when discussing the results.

\subsection{Basis of acceleration ( $R R D D)$}

Only students in high elementary exit test score classes with high enough mathematics and Dutch grades are considered for acceleration. Table 2 shows the descriptive statistics of these measures. In cohort 0 (the cohort where acceleration was not possible) 53 out of 152 students where in a high test class. In cohort 1 and cohort 2 these numbers were respectively 54 out of 159 and 75 out of 189 .

For RDD analyses I would need a threshold for which students who score above that threshold are allowed to accelerate and those below that threshold do not accelerate. Since there is no predefined cut off point to be allowed to accelerate, I apply an fRDD which assumes that, although the probability to be allowed to accelerate does not jump to 1 after the 
cut off, the probability increases for larger values of the forcing variable (Imbens and Lemieux, 2007). The probability to be allowed to accelerate indeed increases by the forcing variables, as can be seen in Figure 2 for mathematics and in Figure 3 for Dutch.

--- Figure 2 here ---

--- Figure 3 here ---

By using fRDD I essentially instrument track placement by passing the threshold of the forcing variable. I estimate the fRDD models using 2SLS and can thus use the first stage to judge the relevance of the instrument. Table 3 shows the first stage of accelerating the mathematics curriculum and the Dutch language curriculum. The first stage shows that for acceleration of mathematics the estimated threshold is relevant, since scoring above the threshold with the period 4 grade is highly significant in predicting acceleration. The results show even that the period 4 grade on its own is not predictive for accelerating mathematics. The estimated threshold also leads to a sufficiently strong first stage, with an F-statistics for the 2SLS analyses of above 10 (Staiger and Stock, 1997; Stock and Yogo, 2005).

--- Table 3 here ---

Table 3 shows that for the Dutch language acceleration the estimated threshold is relevant, but not strong enough. With an F-statistics of 8.8, the first stage is weak. For this reason, in the fRDD analyses I will only focus on the effect of accelerating the mathematics curriculum. ${ }^{6}$

Since the threshold is not an actual (pre-defined) cutoff, but a cutoff I observe in the data, there is no worry that students try to manipulate their grades to be allowed to accelerate. Students are informed that good grades positively influence their chance of being allowed to accelerate, so for them it is best to get as high grades as possible. For this reason I also do not see any discontinuities in the density of the forcing values, as can be seen in Figure 4 for mathematics and Figure 5 for Dutch.

\footnotetext{
${ }^{6}$ I also used both mathematics acceleration and Dutch language acceleration to look at the effect of acceleration on outcomes. However, the F statistic of the first stage was even weaker when I used both types of acceleration.
} 
--- Figure 4 here ---

--- Figure 5 here ---

\subsection{Differences across cohorts and treatment groups}

Since I use different cohorts for my DiD and I rely on these cohorts to be similar, it is important to check whether these cohorts differ on observables. Although the fRDD analyses include cohort fixed effects, also here it is informative to check for differences between cohorts. Table 2 shows only a few significant differences in pre-acceleration skills between the three cohorts.

For the DiD analyses it is also important that the classes with elementary exit test scores equal to or greater than 60 and those with test scores below 60 do not differ between the two years. I test this by applying the estimation method on background characteristics. The treatment should have no effect on these background characteristics since they are revealed before treatment took place. Table 4 shows the results for the elementary exit test score, the elementary teacher recommendation for track placement, relative age in months and examples of a pre-acceleration teacher rated non-cognitive score (asking questions) and the pre-acceleration scores on the national tests (grammar test score).

--- Table 4 here ---

I find that of all the pre-acceleration scores on the national tests in mathematics, Dutch, and general language skills, only the Grammar test score exhibits a treatment effect before treatment has taken place. For the pre-acceleration teacher rated non-cognitive scores, I find that for the sub-competencies asking questions and teamwork, there is a pre-treatment difference between the groups. These significant effects signal that the classes with elementary exit test scores equal to or greater than 60 and those with test scores below 60 between the two years are not fully comparable on these pre-acceleration teacher rated non- 
cognitive scores and the pre-acceleration scores on the national tests. For this reason, for all DiD models estimates are shown without and with pre-acceleration controls. ${ }^{7}$

I do similar pre-acceleration analyses for the fRDD method, in which I estimate the treatment effect on pre-acceleration background characteristics. Here insignificant results show that students are identical around the threshold. ${ }^{8}$ The results show that treatment has a positive "effect" on the pre-acceleration scores on the national tests, which indicates that the students who accelerated were selected on their ability in a non-linear way. ${ }^{9}$ Table 5 shows as examples the results for the mathematics test score and the Dutch vocabulary score. Apparently, those who accelerated the mathematics curriculum where students of highest ability. This is not unexpected, since only the best students were allowed to accelerate. Still, to control for this, all fRDD models include pre-acceleration controls.

--- Table 5 here ---

It is interesting to see that the selection into acceleration was only based on (observed) cognitive measures and not on (observed) non-cognitive measures. Around the threshold, students are identical on the elementary school teacher recommendation used for track placement and on the pre-acceleration teacher rated non-cognitive score (non-cognitive skills).

\section{DiD estimations}

\subsection{Cognitive outcomes}

Table 6 shows the results of the DiD estimation of accelerating the curriculum. I find that students who were considered for accelerating the mathematics and Dutch curriculum score better on certain sub score of the mathematics test (geometry and proportions), worse on numbers, and on the Dutch vocabulary subscore of the language tests in Spring of grade 8.

\footnotetext{
${ }^{7}$ For the attitude scores I unfortunately do not have pre-acceleration scores and therefore I cannot control for preacceleration attitude.

${ }^{8}$ I do not use the elementary school exit test score since, together with the period 4 grades, this was used to decide on treatment status and those above the threshold will by construction have higher elementary exit scores.

${ }^{9}$ Table 2 shows a positive pre-acceleration effect on Dutch vocabulary and mathematics, but there is also a positive pretreatment effect on Dutch reading, general language skills, numbers, geometry, proportions, and connections.
} 
Table 6 present results without and with controlling for the pre-test to remove potential residual endogeneity.

--- Table 6 here ---

The results show that the classes that were considered for acceleration had 0.65 sd higher scores on geometry, 0.4 sd higher scores on proportions, and 0.34 sd higher scores on Dutch vocabulary. These results point to a positive effect of acceleration and show that, besides freeing up room in the curriculum for more learning material, it also led to an increase in cognitive outcomes. The targeted teaching might have motivated those who accelerate to learn more. An alternative explanation is that putting together the high achieveing students together for mathematics and Dutch language (i.e. ability grouping) causes this increase in performance. However, this seems unlikely since the classes that are considered for acceleration are already quite selective on peer quality.

Table 6 also shows a negative effect of acceleration on numbers, if I control for the pre-test. One teachers informed me that he had skipped teaching numbers at all, since he assumed the top students already knew this, to make space in the schedule for the other subjects. This could explain this negative effect. However, as could be seen in Section 4.3 for numbers the parallel trend assumption seemed less reasonable given the pre-acceleration time trends found in Figure 1. The negative effect on numbers is therefore questionable. Acceleration had no effect on the other Dutch language test sub-scores (grammar, spelling, verbs, or reading) or on the other sub score of mathematics (connections).

Since not all students who were considered for acceleration also accelerated, these results are most probably an underestimation. The fRDD results, which are discussed in Section 6, are indeed larger than those found here.

\subsection{Non-cognitive outcomes}

Students who were considered for acceleration scored lower on teacher rated concentration, perseverance, and were less able to have conversations as measured in February of grade 8 (see Appendix A for an explanation of each measure). Table 7 shows that these students score one sd lower on concentration in the class, 0.3 sd lower on perseverance, and 0.4 sd lower on 
conversation skils. Concentration and perseverance are both measured in a school work context, while conversation skills refers to whether the student is able to express himself properly in general. It could be that the pressure from the intensified curriculum led to less concentration and perseverance for subjects which had no intensified curriculum, perhaps because less concentration and perseverance is needed to complete the required work for these students or because the concentration and perseverance reservoir had been depleted by the intensified curriculum in mathematics. This pressure might also explain the decline in conversation skills. Dahman and Anger (2015) present a similar reasoning for the negative effects on emotionally stability that they find from a increased learning intensity.

--- Table 7 here ---

In general, all coefficients of the non-cognitive outcomes have a negative sign. However, only for concentration, perseverance, and conversation skills the possibility to accelerate led to significant lower skills on these subjects.

The students who were considered for acceleration scored signifincantly lower on even more non-cognitive outcomes (results not reported here) if teacher ratings of mathematics and Dutch teachers were included. The Dutch and mathematics teachers are the only teachers who teach the students who accelerate together in one class. For all other courses the students who accelerate are in their original class with students who do not accelerate. This discrepancy seems to suggest a teacher bias for the students who accelerate: the Dutch and mathematics teachers rate the students who accelerate lower, perhaps because they have higher expectations for these students. Alternatively, it could also be that when all the students who accelerate are in one class, they behave differently then when they are together with students who do not accelerate.

\section{6. fRDD estimations}

\subsection{Cognitive outcomes}

Table 8 shows the fRDD results of acceleration on the cognitive outcomes: test scores on the national test at the end of grade 8 in mathematics and language. Similary to the DiD results, I find positive effects on the mathematics sub-score in proportions and geometry. I now also 
find positive effects for numbers. With three out of four subscores being significantly affected be acceleration, consequently also a positive effect on the overall mathematics test score is found, which is shown in the first column. These results show that also the less able students in the high test classes (the marginal students) benefit from accelerating the curriculum, just as seen from the average effect using the DiD method.

--- Table 8 here ---

Since the DiD results only showed the effects on the whole class that was considered for acceleration and the fRDD results show the indivdiual effects of those who accelerated, it was expected that the fRDD results would be bigger. This is indeed the case and the effect sizes are even twice as big: mathematics acceleration leads to a $1.5 \mathrm{sd}$ increase in geometry scores, a $1.1 \mathrm{sd}$ increase in proportions, and a $1.7 \mathrm{sd}$ increase in numbers. However, it should also be kept in mind that in the fRDD analyses I use the two cohorts that were able to accelerate, while in the DiD analyses I used the last cohort that could not accelerate and the first cohort that could accelerate. Furthermore, the fRDD analyses give the effects of acceleration for the marginal students, while the DiD results give an average treatment effect. Also this can explain the differences in the results. And finally, in the DiD I looked at accelerating the mathematics and the Dutch curriculum simultanous, while with the fRDD I isolate the effects of accelerating the mathematics curriculum.

\subsection{Non-cognitive outcomes}

Table 9 shows two examples of the fRDD results of the effect of mathematics acceleration on non-cognitive outcomes. Table 9 shows one positive effect of accelerating the mathematics curriculum: the non-cognitive skill of presenting yourself is increased by $1.2 \mathrm{sd}$. All other non-cognitive outcomes show no effect of acceleration. presenting yourself measures both a form of conscientiousness, since it relates to whether the student is prepared for class, and whether the student is able to express himself. Especially this is of increasing use when the curriculum is intensified and thus this non-cognitive skill is perhaps strengthened for those who accelerate.

--- Table 9 here --- 
Also here it is important to keep in mind that the samples between the DiD analyses and the fRDD analyses changed, that the DiD results can be seen as an underestimation, that the DiD provide average effects while the fRDD present results for the marginal student, and that here I estimate the isolated effect of an acceleration of the mathematics curriculum, while in the DiD I estimate the combined effect of accelerating the mathematics and the Dutch curriculum.

\section{Summary and discussion}

In this paper I evaluate the possibility for high ability vocational students within a secondary school in the Netherlands to accelerate the mathematics and Dutch curriculum. Students that accelerate the curriculum progress through the course material faster, but the curriculum itself, the teaching materials, and the weekly hours taught do not change. By accelerating the curriculum students free up school time in their last year of secondary school to start with post-secondary courses, which gives them an advantage in their further studies. For high ability students with a preference for hands-on vocational education, this policy can be a solution.

To estimate the causal effects of the accelerated curriculum I employ two methods: a Difference-in-Differences (DiD) strategy and a fuzzy Regression Discontinuity Design (fRDD). The results show that after one year the students who accelerated scored significantly higher on certain sub scores on the mathematics tests. Using the DiD, I find that this positive effect is countered by lower scores on the teacher rated scores on perseverance, concentration, and conversation skills. These positive and negative effects points to a possible trade-off for teachers, students, and parents: The students who accelerated will possibly graduate earlier with higher cognitive skills, but with lower non-cognitive skills. For the marginal student (using an fRDD), I find almost no results on non-cognitive outcomes.

Since both methods find similar results the positive effects on the mathematics test scores, these are most likely due accelerating the mathematics curriculum, and not due to accelerating the Dutch curriculum. However, the fRDD results are much larger. The results are expected to differ between the DiD and the fRDD analyses for four reasons: First, the DiD results give an underestimation of the effect since not all students in classes which were considered for acceleration actually accelerate. The larger fRDD results are consistent with 
this expectation. Second, the samples used in the two analyses differ: in the DiD analyses I used the last cohort that could not accelerate, and the first cohort that could accelerate, while in the fRDD analyses I use the first two cohorts that were able to accelerate. Third, the fRDD analyses give the effects of acceleration for the marginal students, while the DiD results give an average treatment effect. Fourth, the DiD analyses are unable to differentiate between accelerating the mathematics curriculum and the Dutch curriculum, while in the fRDD I only look at the effects of accelerating the mathematics curriculum. For this reason the effects on the mathematics test scores are most likely due to the accelerated mathematics curriculum and not due to the accelerated Ducth curriculum. Regardless of these differences in the analyses, both methods show positive effects of acceleration the curriculum on subscores of the mathematics tests strengtening the confidence in these results.

The school policy discussed here captures similar mechanisms as tracking students into distinct educational programs. However, contrary to the tracking literature, here I am able to focus on one specific aspect of tracking: faster progression through the curriculum. The curriculum itself stays constant, while also the resources do not differ between classes that accelerate and those that do not. With tracking all these aspects change simultaneously. Ability grouping, in which students of similar ability are grouped together, also captures only one aspect of tracking: the change in peers in the class. Previous literature has found positive effects of ability grouping on student performance (e.g. Figlio and Page, 2000; Duflo et al., 2011). Therefore, since both acceleration of the curriculum and peer effects show positive effects, the lack of consensus in the tracking literature could only be due to the other aspects of tracking not captured by acceleration of the curriculum or by peer effects: different resources and different curricula between tracks. Further research can shed more light on this issue. 


\section{References}

Borghans, L. and R. Diris (2014) Allocating Instruction Time: How Language Instruction Can Affect Multiple Skills. Journal of Human Capital, 8(2), pp. 161-198.

Cortes, K., J. Goodman, T. Nomi (2015) Intensive Math Instruction and Educational Attainment: Long- Run Impacts of Double- Dose Algebra. Journal of Human Resources, 50(1), pp. 108-158.

Dahmann, S. and S. Anger (2014) The Impact of Education on Personality: Evidence from a German High School Reform. IZA Discussion Paper Series, no. 8139. Bonn: IZA.

Duflo E, P. Dupas, and M. Kremer (2011) Peer effects, teacher incentives, and the impact of tracking: Evidence from a randomized evaluation in Kenya. American Economic Review, 101, pp.: 1739-1774.

Figlio, D. and M. Page (2000) School Choice and the Distributional Effects of Ability Tracking: Does Separation Increase Inequality? Journal of Urban Economics, 51, pp. 497-514.

Hanushek, E., and L. Woessmann (2006) Does Educational Tracking Affect Performance and Inequality? Difference-in-differences Evidence Across Countries. Economic Journal, 116, pp. C63-C76.

Huebener, M. and J. Marcus (2015) Moving up a gear: The impact of compressing instructional time into fewer years of schooling. DIW Discussion Papers, no. 1450.

Imbens, G. and T. Lemieux (2007) Regression Discontinuity Designs: A Guide to Practice. Journal of Econometrics, 142(2), pp. 615-635.

Lavy, V. (2015) Do Differences In Schools' Instruction Time Explain International Achievement Gaps? Evidence From Developed And Developing Countries. The Economic Journal, 125 (November), F397-F424.

Lee, D. and T. Lemieux (2010) Regression Discontinuity Designs in Economics, Journal of Economic Literature, 48(June), pp. 281-355.

Korthals, R. (2015) Tracking Students in Secondary Education: Consequences for Student Performance and Inequality. $\mathrm{PhD}$ thesis, Maastricht University.

Rivkin, S. and J. Schiman (2015) Instruction Time, Classroom Quality, And Academic Achievement, The Economic Journal, 125 (November), F425-F448.

Staiger, D. and J. Stock (1997) Instrumental Variables Regression with Weak Instruments. Econometrica, 65(3), pp. 557-586. 
Stock, J. and M. Yogo (2005) Testing for Weak Instruments in Linear IV Regression. In: D. Andrews, J. Stock, T. Rothenberg (eds) Identification and inference for econometric models: Essays in honor of Thomas Rothenberg, pp. 80-108. New York: Cambridge University Press.

Van Elk, R., M. van der Steeg, and D. Webbink (2011) Does the Timing of Tracking Affect Higher Education Completion? Economics of Education Review, 30(5), pp. 10091021. 
FIGURES 
Figure 1: Pre- and post-policy trends for various outcomes (high test classes dashed line, non-high test classes solid line)

a. Mathematics (overall)

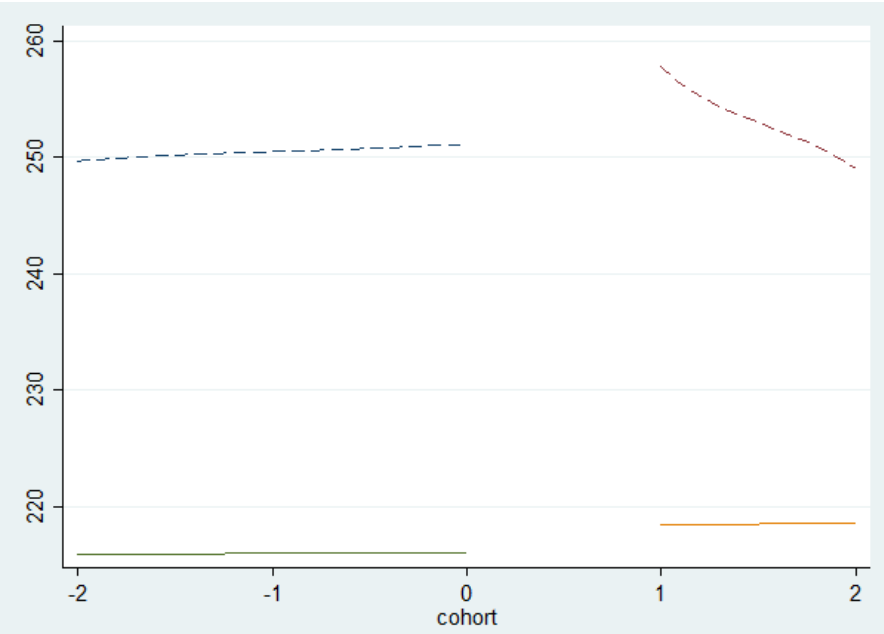

\section{d. Numbers}

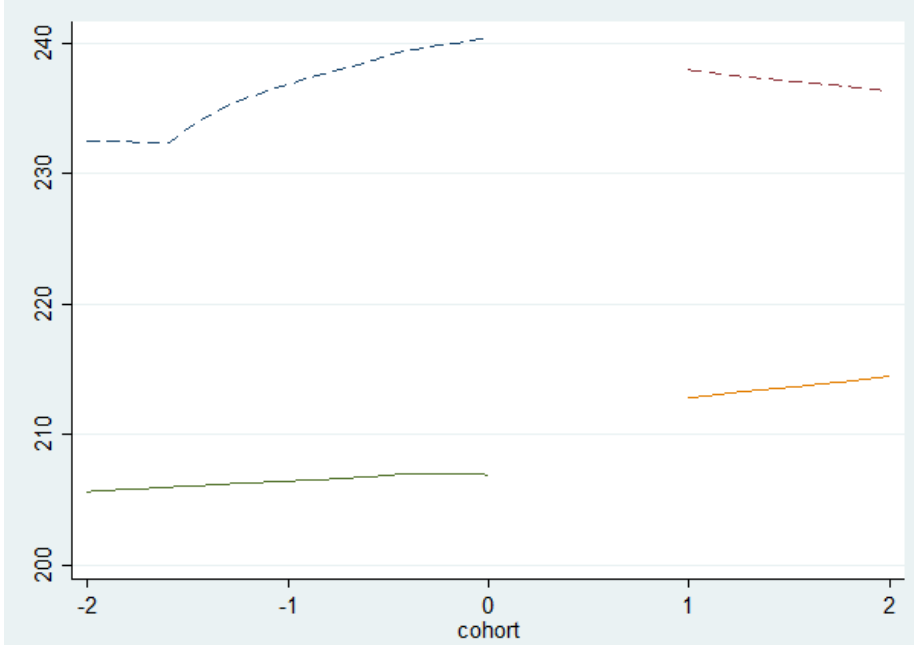

\section{b. Geometry}

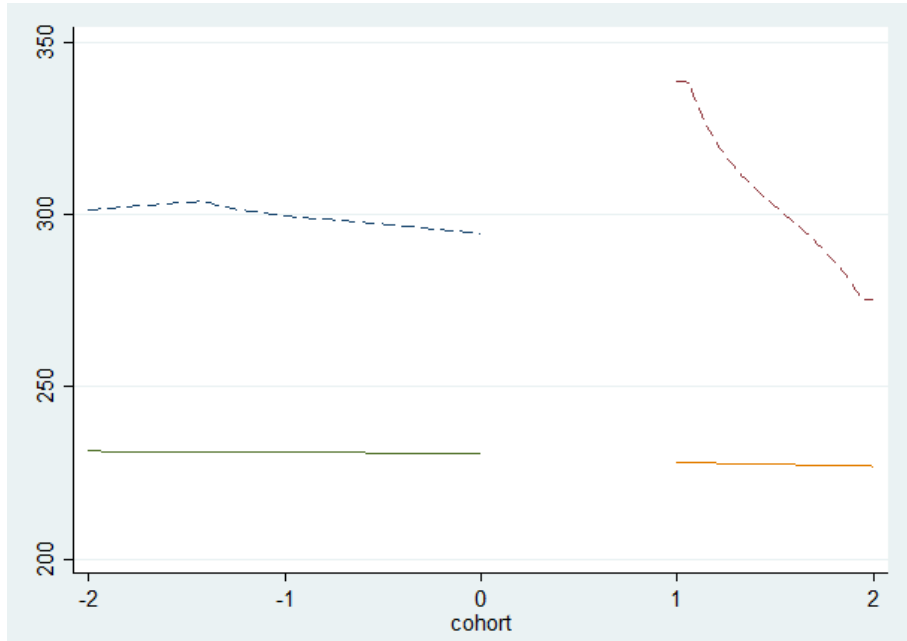

\section{e. Dutch vocabulary}

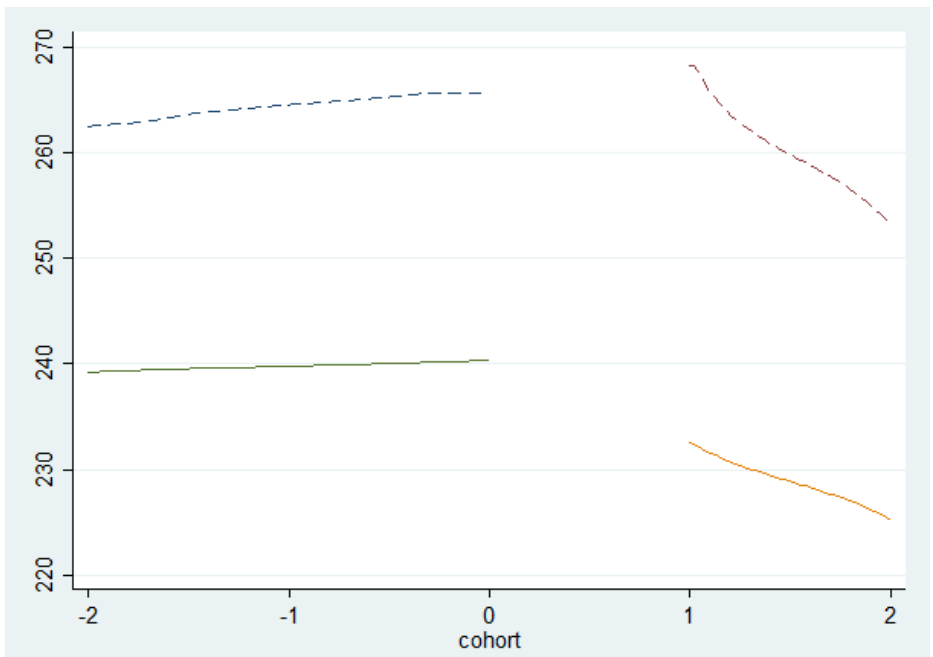

c. Proportions

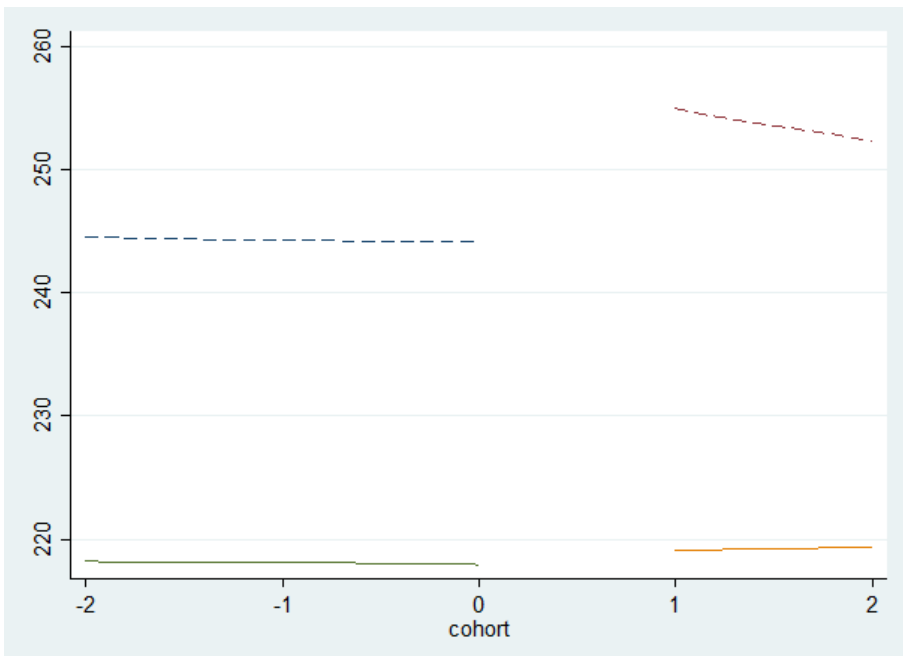

\section{d. Grammar}

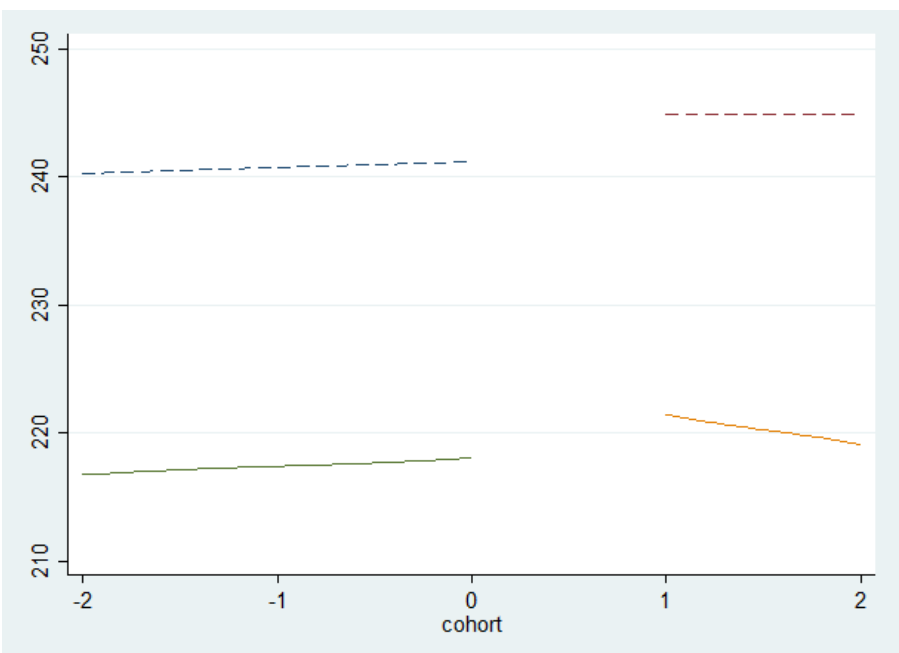


Figure 2: Probability to accelerate the mathematics curriculum over the period 4 mathematics grade

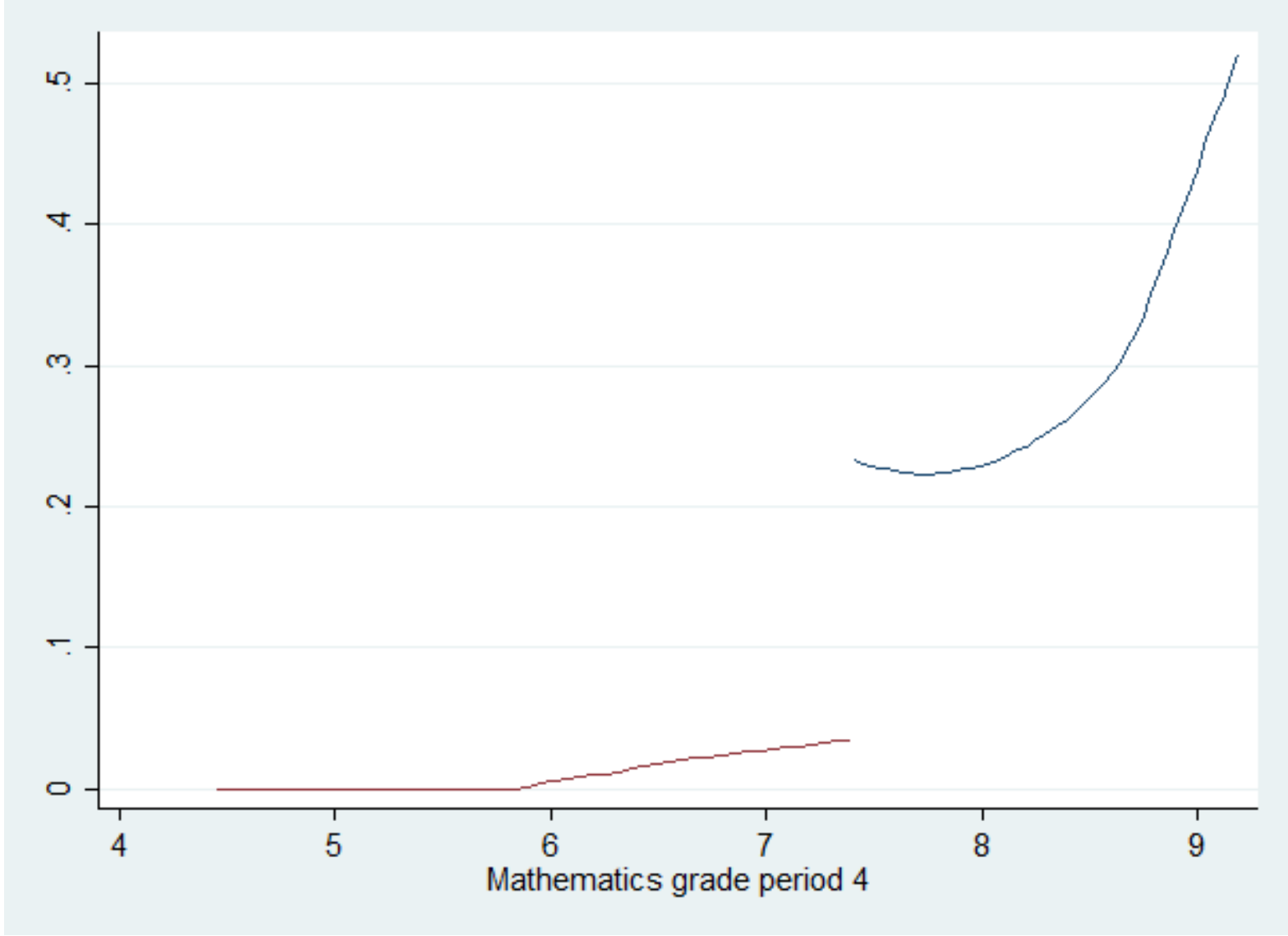

Notes: two polynomials with a break at the estimated threshold, only when a minimum of 2 students have the two-digit grade 
Figure 3: Probability to accelerate the language curriculum over the period 4 language grade

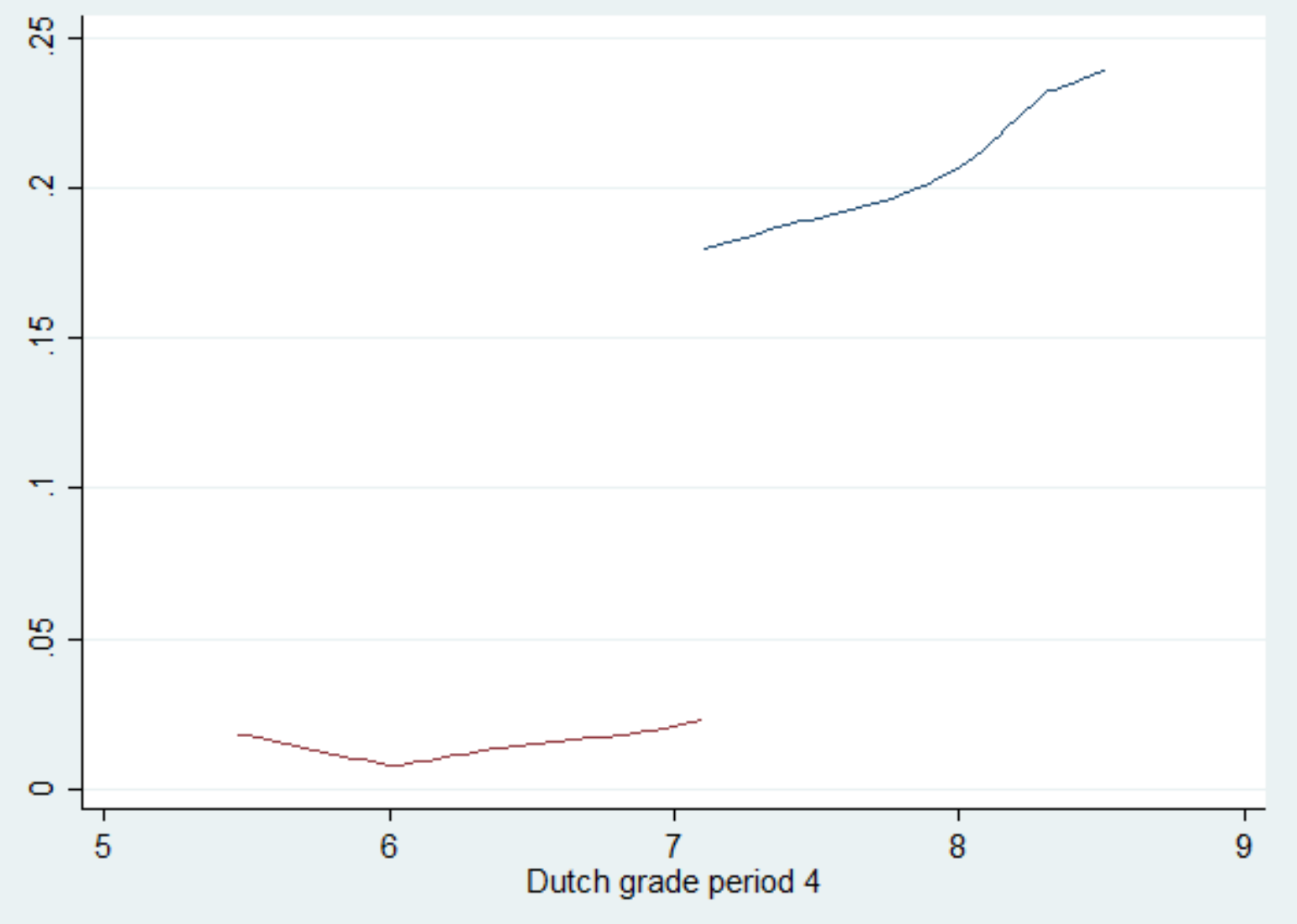

Notes: two polynomials with a break at the estimated threshold, only when a minimum of 2 students have the two-digit grade 
Figure 4: Density of the period 4 mathematics grade

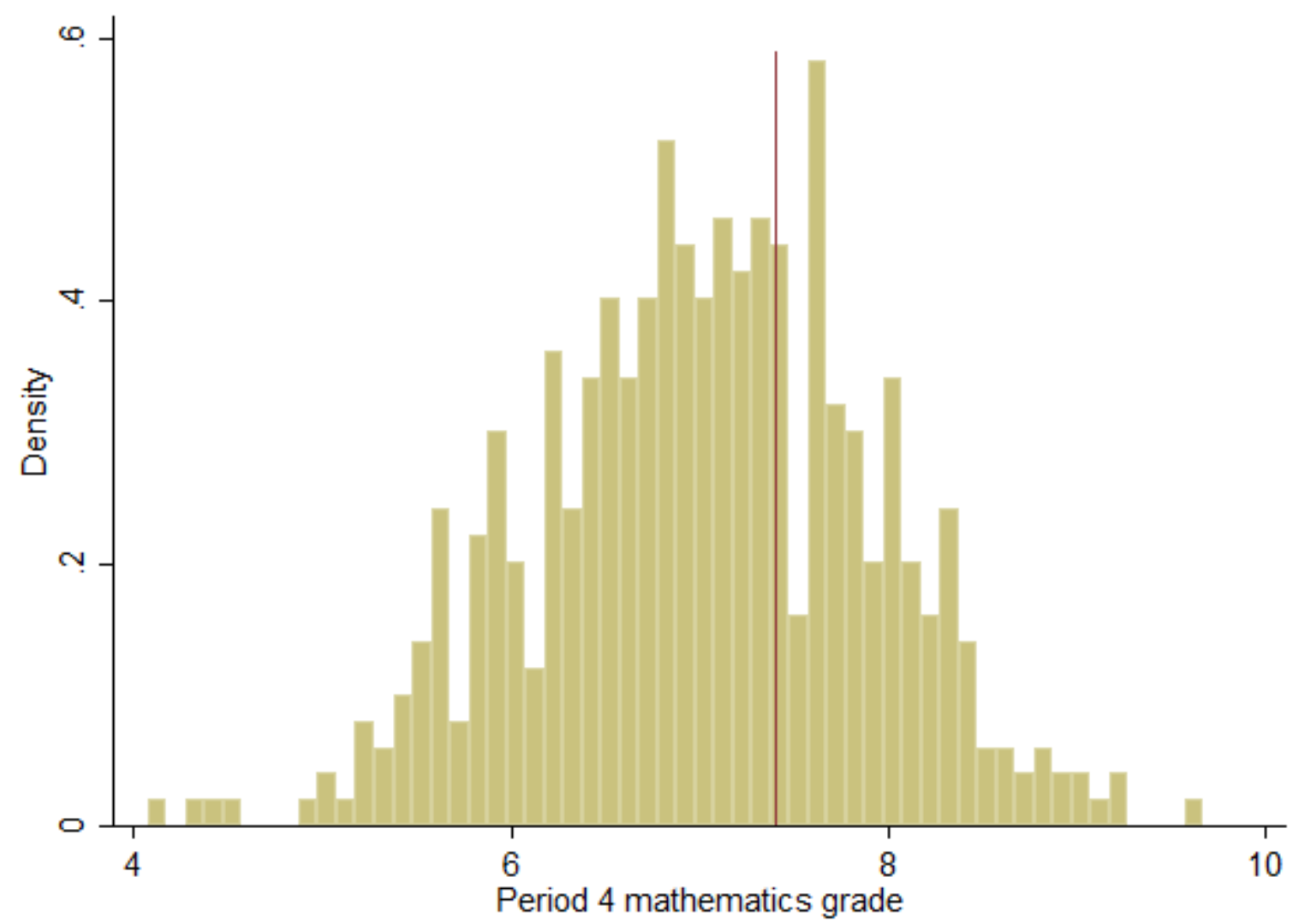

Notes: The red line shows the threshold. 
Figure 5: Density of the period 4 Dutch language grade

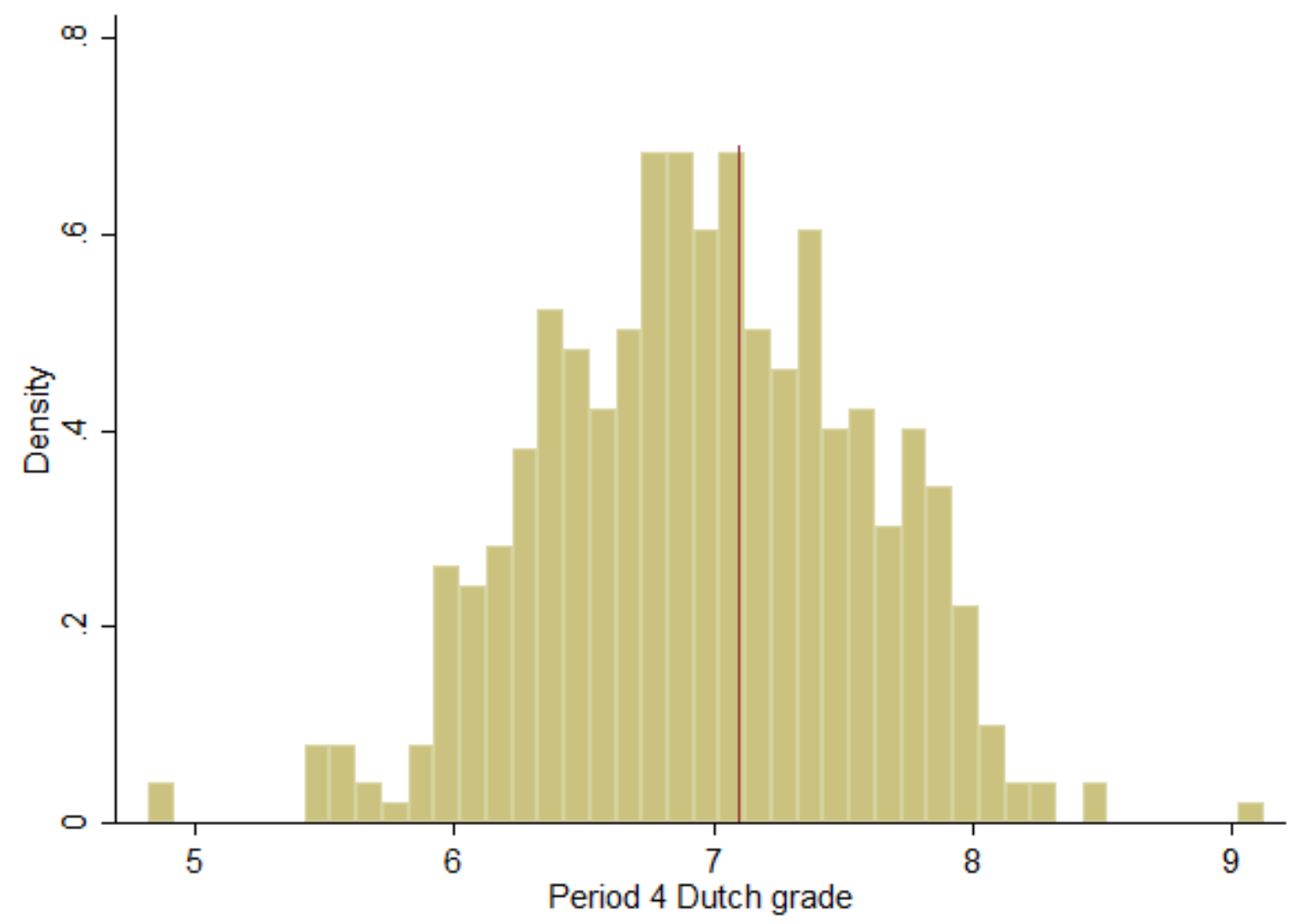

Notes: The red line shows the threshold. 
TABLES 
Table 1: Mean elementary school exit test score per grade 7 class

\begin{tabular}{|c|c|c|c|c|c|}
\hline School year: & $2010 / 2011$ & $2011 / 2012$ & $2012 / 2013$ & $2013 / 2014$ & $2014 / 2015$ \\
\hline Cohort: & Cohort -2 & Cohort -1 & Cohort 0 & Cohort 1 & Cohort 2 \\
\hline & Pre-policy & Pre-policy & Pre-policy & Policy & Policy \\
\hline Class name & period & period & period & period & period \\
\hline $1 \mathrm{~A}$ & 36.7 & 32.0 & 40.0 & 28.4 & 32.4 \\
\hline 1B & 37.3 & 32.3 & 42.0 & 30.8 & 31.5 \\
\hline $1 \mathrm{C}$ & 44.3 & 46.3 & 48.5 & 46.9 & 40.0 \\
\hline $1 \mathrm{D}$ & 57.6 & 48.4 & 53.2 & 45.5 & 44.1 \\
\hline $1 \mathrm{E}$ & 56.9 & 54.6 & 51.7 & 54.8 & 53.3 \\
\hline $1 \mathrm{~F}$ & 71.3 & 72.6 & 73.1 & 56.2 & 48.8 \\
\hline $1 \mathrm{G}$ & & & 72.2 & $69.3 *$ & $72.3^{*}$ \\
\hline $1 \mathrm{H}$ & & & & $74.2 *$ & $70.0^{*}$ \\
\hline $1 \mathrm{~J}^{\mathrm{a}}$ & & & & & $68.8^{*}$ \\
\hline Used in DiD & - & - & $\sqrt{ }$ & $\sqrt{ }$ & - \\
\hline Used in fRDD & - & - & - & $\sqrt{ }$ & $\sqrt{ }$ \\
\hline
\end{tabular}

Notes: ${ }^{\mathrm{a}}$ There is no class 1I since the similar appearance of 1 and I cause confusion in the schedule. The possible test score ranges from 0 to 100 . This table is made using data from all first year students, including those who left after year 1. Classes with an asterisk (*), the high test classes, were eligible to accelerate the curriculum after the policy was introduced (for cohort 1 and 2). 
Table 2: Descriptive statistics of background (grade 6 and 7) and outcome variables (grade 8)

\begin{tabular}{|c|c|c|c|c|c|c|}
\hline Variable & $\mathrm{N}$ & $\begin{array}{l}\text { Cohort } 0 \\
\text { Mean (sd) }\end{array}$ & $\mathrm{N}$ & $\begin{array}{l}\text { Cohort } 1 \\
\text { Mean (sd) }\end{array}$ & $\mathrm{N}$ & $\begin{array}{l}\text { Cohort } 2 \\
\text { Mean (sd) }\end{array}$ \\
\hline \multicolumn{7}{|c|}{ Background (grade 6) } \\
\hline Elem. teacher recom. & 147 & $5.4(3.1)$ & 149 & $5.4(3.2)$ & 185 & $5.8(3.1)$ \\
\hline Relative age & 152 & $6.8(3.5)$ & 159 & $6.7(3.5)$ & 186 & $6.7(3.6)$ \\
\hline \multicolumn{7}{|c|}{ Basis for acceleration (grade 6 and 7) } \\
\hline Elementary exit test score & 132 & $58.2(7.6)$ & 135 & $56.8(8.6)$ & 150 & $55.6(8.6)$ \\
\hline High test class $(\%)$ & 152 & $0.35(0.5)$ & 159 & $0.34(0.5)$ & 189 & $0.40(0.5)$ \\
\hline P4 Math & 152 & $7.0(0.9)$ & 159 & $7.0(0.8)$ & 186 & $7.0(0.9)$ \\
\hline P4 Dutch & 152 & $7.0(.06)$ & 159 & $7.0(0.6)$ & 186 & $6.9(0.7)$ \\
\hline \multicolumn{7}{|c|}{ Acceleration (grade 7 and 8) } \\
\hline Math $(\%)$ & 152 & $0.00(0.00)^{* * *}$ & 159 & $0.14(0.35)$ & 189 & $0.13(0.34)$ \\
\hline Dutch $(\%)$ & 152 & $0.00(0.00)^{* * *}$ & 159 & $0.13(0.34)$ & 189 & $0.13(0.33)$ \\
\hline \multicolumn{7}{|c|}{ Pre-acceleration: Cognitive skills (standardized tests, grade 7) } \\
\hline Mathematics & 152 & $215.2(25.2)$ & 158 & $214.6(27.1)$ & 185 & $215.6(26.8)$ \\
\hline Numbers & 152 & $212.4(26.3)$ & 158 & $214.1(29.5)$ & 185 & $212.7(28.8)$ \\
\hline Geometry & 152 & $218.8(30.1)$ & 158 & $218.6(32.9)$ & 185 & $220.5(35.0)$ \\
\hline Connections & 152 & $215.6(36.0)$ & 158 & $213.3(34.2)$ & 185 & $217.2(39.6)$ \\
\hline Proportions & 152 & $213.9(25.5)$ & 158 & $212.5(27.7)$ & 185 & $212.9(24.7)$ \\
\hline Dutch reading & 152 & $206.7(15.1)$ & 158 & $208.5(14.5)$ & 185 & $208.4(14.9)$ \\
\hline Dutch vocabulary & 152 & $231.3(30.5)$ & 158 & $231.2(28.5)$ & 185 & $227.9(24.0)$ \\
\hline Grammar & 152 & $197.8(30.6)$ & 158 & $198.8(29.3)$ & 185 & $197.4(34.6)$ \\
\hline Non verb spelling & 152 & $199.8(24.4)$ & 158 & $202.5(25.4)$ & 185 & $200.0(23.9)$ \\
\hline Verb spelling & 152 & $199.2(26.8)$ & 158 & $200.7(34.3)$ & 185 & $198.4(27.1)$ \\
\hline General language skills & 152 & $198.6(22.4)$ & 158 & $200.3(21.6)$ & 185 & $198.7(24.3)$ \\
\hline \multicolumn{7}{|c|}{ Pre acceleration: Non-cognitive skills (teacher rated, grade 7) } \\
\hline Active listening & 147 & $0.6(0.1)$ & 157 & $0.6(0.1)$ & 183 & $0.6(0.1)$ \\
\hline Keeping appointments & 147 & $0.7(0.1)^{* * *}$ & 157 & $0.7(0.1)$ & 183 & $0.7(0.1)$ \\
\hline Teamwork & 147 & $0.6(0.1)$ & 157 & $0.6(0.1)$ & 183 & $0.6(0.1)$ \\
\hline Cooperation (av. score) & 147 & $0.7(0.1)^{*}$ & 157 & $0.6(0.1)$ & 183 & $0.6(0.1)$ \\
\hline Presenting yourself & 147 & $0.6(0.1)$ & 157 & $0.6(0.1)$ & 183 & $0.6(0.1)$ \\
\hline Conversation skills & 147 & $0.6(0.1)$ & 157 & $0.6(0.1)$ & 183 & $0.6(0.1)$ \\
\hline Asking questions & 147 & $0.6(0.2)$ & 157 & $0.6(0.1)$ & 183 & $0.6(0.1)$ \\
\hline Communication (av. score) & 147 & $0.6(0.1)$ & 157 & $0.6(0.1)$ & 183 & $0.6(0.1)$ \\
\hline \multicolumn{7}{|c|}{ Outcome: Cognitive skills (standardized tests, grade 8) } \\
\hline Mathematics & 147 & $228.6(28.1)$ & 159 & $232.5(29.5)$ & 184 & $230.3(27.5)$ \\
\hline Numbers & 147 & $219.6(33.4)$ & 159 & $220.9(25.6)$ & 184 & $223.6(29.6)$ \\
\hline Geometry & 147 & $250.3(56.5)^{* * *}$ & 159 & $267.4(84.7)$ & 184 & $244.6(53.0)^{* * *}$ \\
\hline Connections & 147 & $213.5(26.5)$ & 159 & $217.5(26.9)$ & 184 & $215.7(24.1)$ \\
\hline Proportions & 147 & $227.5(31.7)$ & 159 & $232.0(33.6)$ & 184 & $231.9(35.5)$ \\
\hline Dutch reading & 147 & $229.6(23.3)$ & 159 & $231.6(20.8)$ & 184 & $231.3(19.4)$ \\
\hline Dutch vocabulary & 147 & $250.3(24.7)$ & 159 & $246.6(31.9)$ & 184 & $234.9(32.0)^{* * *}$ \\
\hline Grammar & 147 & $228.8(25.4)$ & 159 & $230.8(24.5)$ & 184 & $228.1(26.3)$ \\
\hline Non verb spelling & 147 & $221.7(22.5)$ & 159 & $224.6(20.6)$ & 184 & $223.5(23.2)$ \\
\hline Verb spelling & 147 & $219.6(25.1)$ & 159 & $223.8(25.9)$ & 184 & $219.8(21.8)$ \\
\hline General language skills & 147 & $222.7(19.1)$ & 159 & $226.3(19.7)$ & 184 & $224.7(19.8)$ \\
\hline
\end{tabular}

Outcome: Non-cognitive skills (teacher rated, grade 8) 


\begin{tabular}{lllllll} 
Active listening & 150 & $0.6(0.2)$ & 157 & $0.7(0.1)$ & 187 & $0.5(0.2)^{* * *}$ \\
Keeping appointments & 150 & $0.6(0.1)^{* * *}$ & 157 & $0.7(0.1)$ & 187 & $0.7(0.1)$ \\
Teamwork & 150 & $0.6(0.1)^{*}$ & 157 & $0.6(0.1)$ & 187 & $0.2(0.0)^{* * *}$ \\
Cooperation (av. score) & 150 & $0.6(0.1)^{* *}$ & 157 & $0.7(0.1)$ & 187 & $0.5(0.1)^{* * *}$ \\
Presenting yourself & 150 & $0.7(0.2)$ & 157 & $0.7(0.1)$ & 162 & $0.4(0.3)^{* * *}$ \\
Conversation skills & 150 & $0.6(0.2)$ & 157 & $0.6(0.1)$ & 0 & \\
Asking questions & 150 & $0.6(0.2)$ & 157 & $0.7(0.1)$ & 187 & $0.7(0.1)$ \\
Communication (av. score) & 150 & $0.6(0.2)$ & 157 & $0.7(0.1)$ & 187 & $0.5(0.2)^{* * *}$ \\
Independence & 150 & $0.6(0.2)$ & 157 & $0.6(0.1)$ & 187 & $0.5(0.2)^{* * *}$ \\
Perseverance & 150 & $0.6(0.1)$ & 157 & $0.6(0.1)$ & 187 & $0.4(0.1)^{* * *}$ \\
Concentration & 150 & $0.7(0.2)$ & 157 & $0.7(0.2)$ & 187 & $0.6(0.1)$ \\
Attitude (av. score) & 150 & $0.6(0.1)$ & 157 & $0.6(0.1)$ & 187 & $0.5(0.1)^{* * *}$ \\
\hline
\end{tabular}
Notes: The asterisks * $* *$, and $* * *$ indicate significant difference from the cohort 1 mean at the $10 \%, 5 \%$, and $1 \%$ levels, respectively. 
Table 3: First stage results for accelerating the mathematics and Dutch language curriculum (using the sample of the mathematics test)

\begin{tabular}{lcc} 
& $\begin{array}{c}\text { Acceleration of } \\
\text { Mathematics }\end{array}$ & $\begin{array}{c}\text { Acceleration of } \\
\text { Dutch }\end{array}$ \\
\hline Period 4 grade>=threshold & $0.216^{* * *}$ & $0.165^{* * *}$ \\
& $(0.059)$ & $(0.056)$ \\
Period 4 grade & 0.022 & 0.046 \\
& $(0.023)$ & $(0.040)$ \\
Pre-test & $0.105^{* * *}$ & $0.093^{* * *}$ \\
& $(0.018)$ & $(0.017)$ \\
Cohort & -0.020 & -0.014 \\
& $(0.032)$ & $(0.033)$ \\
& & \\
\# of students & 341 & 341 \\
$\mathrm{R}^{2}$ & 0.294 & 0.225 \\
F-test in 2SLS & 13.530 & 8.752
\end{tabular}

Notes: Robust standard errors in parentheses. Models controlled for previous score and constant. The asterisks *, **, and $* * *$ indicate significance at the $10 \%, 5 \%$, and $1 \%$ levels, respectively. "Period 4 grade>=threshold" is a dummy variable which is one is the student has a period 4 Mathematics or Dutch grade above the calculated threshold (74/100 in Mathematics and 71/100 in Dutch); the period 4 grade runs from 0 to 100; the pre-test is standardized. 
Table 4: Pre-treatment effects of the treatment: DiD

\begin{tabular}{lccccc} 
& $\begin{array}{c}\text { Elementary } \\
\text { exit test } \\
\text { score }\end{array}$ & $\begin{array}{c}\text { Elementary } \\
\text { teacher } \\
\text { recom. }\end{array}$ & $\begin{array}{c}\text { Relative } \\
\text { age }\end{array}$ & $\begin{array}{c}\text { Grammar test } \\
\text { score }\end{array}$ & $\begin{array}{c}\text { Asking } \\
\text { questions }\end{array}$ \\
\hline Treatment & 0.485 & 0.662 & 0.083 & $0.373^{*}$ & $-0.469^{* *}$ \\
Cohort & $(1.272)$ & $(0.459)$ & $(0.860)$ & $(0.212)$ & $(0220)$ \\
& -0.856 & -0.204 & -0.042 & -0.085 & 0.072 \\
High test class & $11.790 * * *$ & $4.827 * * *$ & 0.036 & $0.706^{* * *}$ & $0.036 * * *$ \\
& $(0.840)$ & $(0.356)$ & $(0.619)$ & $(0.159)$ & $(0.157)$ \\
\# of students & 267 & 296 & 311 & 310 & 304 \\
$\mathrm{R}^{2}$ & 0.526 & 0.589 & 0.000 & 0.212 & 0.156 \\
\hline
\end{tabular}

Notes: Robust standard errors in parentheses. The asterisks *,**, and *** indicate significance at the $10 \%, 5 \%$, and $1 \%$ levels, respectively. The constant is excluded from the table. The dependent variables grammar test score and the score on asking questions are standardized, the others are as shown in Table 2. All shown independent variables are dummy variables. 
Table 5: Pre-treatment effects of the treatment: fRDD with acceleration in mathematics

\begin{tabular}{|c|c|c|c|c|c|}
\hline & $\begin{array}{c}\text { Elementary } \\
\text { teacher }\end{array}$ & Relative & & Dutch & \\
\hline & recom. & age & Mathematics & vocabulary & Cooperation \\
\hline Acceleration & 3.035 & 1.702 & $1.449 * *$ & $2.339 * * *$ & -0.414 \\
\hline & $(2.143)$ & $(2.510)$ & $(0.622)$ & $(0.781)$ & $(0.670)$ \\
\hline Period 4 grade & 0.130 & -0.594 & $0.199 *$ & $-0.290 * *$ & $0.529 * * *$ \\
\hline & $(0.381)$ & $(0.426)$ & $(0.108)$ & $(0.127)$ & $(0.130)$ \\
\hline Cohort & 0.427 & -0.048 & 0.062 & -0.081 & -0.082 \\
\hline & $(0.312)$ & $(0.388)$ & $(0.099)$ & $(0.115)$ & $(0.098)$ \\
\hline \# of students & 334 & 344 & 343 & 343 & 337 \\
\hline $\mathrm{R}^{2}$ & 0.203 & & 0.219 & & 0.117 \\
\hline
\end{tabular}

Notes: Robust standard errors in parentheses. The asterisks *, **, and *** indicate significance at the $10 \%, 5 \%$, and $1 \%$ levels, respectively. The constant is excluded from the table. The dependent variables Mathematics, Dutch vocabulary, and Cooperation are standardized, the others are as shown in Table 2. Acceleration and Cohort are dummy variables; the period 4 mathematics grade runs from 0 to 100 . 
Table 6: DiD estimates of the effects of accelerating the curriculum on cognitive outcomes

\begin{tabular}{|c|c|c|c|c|c|c|c|c|}
\hline & Geometry & Geometry & Proportions & Proportions & Numbers & Numbers & $\begin{array}{c}\text { Dutch } \\
\text { vocabulary }\end{array}$ & $\begin{array}{c}\text { Dutch } \\
\text { vocabulary }\end{array}$ \\
\hline \multirow[t]{2}{*}{ Treatment } & $0.704 * * *$ & $0.649 * * *$ & $0.483 * *$ & $0.402 *$ & -0.230 & $-0.365^{*}$ & 0.285 & $0.339 * *$ \\
\hline & $(0.255)$ & $(0.244)$ & $(0.226)$ & $(0.210)$ & $(0.226)$ & $(0.209)$ & $(0.185)$ & $(0.166)$ \\
\hline \multirow[t]{3}{*}{ Cohort } & 0.044 & 0.063 & -0.014 & 0.039 & 0.147 & $0.166^{*}$ & $-0.204^{*}$ & $-0.239 * *$ \\
\hline & $(0.088)$ & $(0.084)$ & $(0.101)$ & $(0.0847)$ & $(0.103)$ & $(0.094)$ & $(0.122)$ & $(0.108)$ \\
\hline & $0.941 * * *$ & $0.639 * * *$ & $0.735^{* * *}$ & $0.285^{*}$ & $1.244 * * *$ & $0.855^{* * *}$ & $0.777 * * *$ & $0.372 * * *$ \\
\hline High test class & $(0.146)$ & $(0.141)$ & $(0.171)$ & $(0.156)$ & $(0.190)$ & $(0.164)$ & $(0.129)$ & $(0.121)$ \\
\hline Pre test & - & $\sqrt{ }$ & - & $\sqrt{ }$ & - & $\sqrt{ }$ & - & $\sqrt{ }$ \\
\hline \# of students & 305 & 305 & 305 & 305 & 305 & 305 & 305 & 305 \\
\hline $\mathrm{R}^{2}$ & 0.352 & 0.420 & 0.251 & 0.409 & 0.292 & 0.414 & 0.231 & 0.393 \\
\hline
\end{tabular}

Notes: Robust standard errors in parentheses. The asterisks *,**, and *** indicate significance at the $10 \%, 5 \%$, and $1 \%$ levels, respectively. Constant and pre-test excluded from table. The dependent variables are standardized. All reported independent variables are dummy variables. 
Table 7: DiD estimates of the effects of accelerating the curriculum on non-cognitive outcomes.

\begin{tabular}{lcccc} 
& Conversation & Conversation & Perseverance & Concentration \\
\hline Treatment & $-0.409 * *$ & $-0.397 * *$ & $-0.337 * *$ & $-1.090^{* * *}$ \\
& $(0.181)$ & $(0.173)$ & $(0.156)$ & $(0.235)$ \\
Cohort & $0.204 *$ & $0.220^{*}$ & 0.148 & $0.340^{* *}$ \\
& $(0.120)$ & $(0.116)$ & $(0.102)$ & $(0.137)$ \\
High test class & $1.522 * * *$ & $1.333^{* * *}$ & $1.060^{* * *}$ & $1.386^{* * *}$ \\
& $(0.151)$ & $(0.143)$ & $(0.117)$ & $(0.151)$ \\
Pre-test & - & $\sqrt{ }$ & - & - \\
& & & & 307 \\
\# of students & 300 & 300 & 307 & 0.193 \\
$\mathrm{R}^{2}$ & 0.405 & 0.454 & 0.289 &
\end{tabular}

Notes: Robust standard errors in parentheses. The asterisks *,**, and *** indicate significance at the $10 \%, 5 \%$, and $1 \%$ levels, respectively. The constant and pre-test are excluded from the table. The dependent variables are standardized. All reported independent variables are dummy variables. 
Table 8: fRDD estimates of the effects of accelerating the mathematics curriculum on cognitive outcomes

\begin{tabular}{|c|c|c|c|c|c|c|c|c|}
\hline \multirow[b]{2}{*}{ Method: } & \multicolumn{2}{|c|}{ Math } & \multicolumn{2}{|c|}{ Geometry } & \multicolumn{2}{|c|}{ Proportions } & \multicolumn{2}{|c|}{ Numbers } \\
\hline & OLS & IV & OLS & IV & OLS & IV & OLS & IV \\
\hline Acceleration & $0.617 * * *$ & $1.300 * *$ & $1.147 * * *$ & $1.518^{* *}$ & $0.508 * * *$ & $1.142^{*}$ & $0.409 * * *$ & $1.777 * *$ \\
\hline & $(0.133)$ & $(0.565)$ & $(0.197)$ & $(0.669)$ & $(0.177)$ & $(0.656)$ & $(0.147)$ & $(0.774)$ \\
\hline Period 4 grade & $0.173 * * *$ & 0.098 & $0.164 * * *$ & 0.118 & $0.178 * * *$ & 0.100 & $0.142 * *$ & -0.025 \\
\hline & $(0.043)$ & $(0.070)$ & $(0.049)$ & $(0.085)$ & $(0.0557)$ & (0.093) & $(0.056)$ & $(0.106)$ \\
\hline Cohort & -0.096 & -0.082 & $-0.345^{* * *}$ & $-0.337 * * *$ & -0.010 & 0.001 & 0.106 & 0.123 \\
\hline & $(0.067)$ & $(0.071)$ & $(0.087)$ & $(0.088)$ & $(0.087)$ & $(0.090)$ & $(0.082)$ & (0.093) \\
\hline \# of students & 341 & 341 & 341 & 341 & 341 & 341 & 341 & 341 \\
\hline $\mathrm{R}^{2}$ & 0.629 & 0.589 & 0.455 & 0.444 & 0.396 & 0.361 & 0.332 & 0.136 \\
\hline F-test & & 13.530 & & 15.620 & & 14.932 & & 14.244 \\
\hline
\end{tabular}

Notes: Robust standard errors in parentheses. The constant and pre-test are excluded from the table. The asterisks *, **, and *** indicate significance at the $10 \%, 5 \%$, and $1 \%$ levels, respectively. The dependent variables are standardized. Acceleration and Cohort are dummy variables; the period 4 mathematics grade runs from 0 to 100 . 
Table 9: fRDD estimates of the effects of accelerating the mathematics curriculum on noncognitive outcomes

\begin{tabular}{|c|c|c|c|c|}
\hline \multirow[b]{2}{*}{ Method: } & \multicolumn{2}{|c|}{ Presenting yourself } & \multicolumn{2}{|c|}{ Concentration } \\
\hline & OLS & IV & OLS & IV \\
\hline \multirow[t]{2}{*}{ Acceleration } & 0.0403 & $1.164^{*}$ & $0.398 * * *$ & 0.509 \\
\hline & $(0.148)$ & $(0.649)$ & $(0.152)$ & $(0.586)$ \\
\hline \multirow[t]{2}{*}{ Math grade P4 } & 0.0798 & -0.0585 & $0.343 * * *$ & $0.326^{* * *}$ \\
\hline & $(0.0734)$ & $(0.104)$ & $(0.0563)$ & $(0.102)$ \\
\hline \multirow[t]{2}{*}{ Cohort } & $-1.081 * * *$ & $-1.024 * * *$ & -0.100 & -0.0981 \\
\hline & $(0.0987)$ & $(0.110)$ & $(0.0968)$ & $(0.0982)$ \\
\hline \# of students & 309 & 309 & 341 & 341 \\
\hline $\mathrm{R}^{2}$ & 0.336 & 0.233 & 0.162 & 0.160 \\
\hline F-test & & 17.795 & & 17.576 \\
\hline
\end{tabular}

Notes: Robust standard errors in parentheses. The constant and pre-test are excluded from the table. The dependent variables are standardized. Acceleration and Cohort are dummy variables; the period 4 mathematics grade runs from 0 to 100 . 


\section{APPENDIX A}

\section{$\underline{\text { Non-cognitive skills (grade } 7 \text { and } 8 \text { ) }}$}

All sub competencies are rated by teachers on a scale from 1 to 5 .

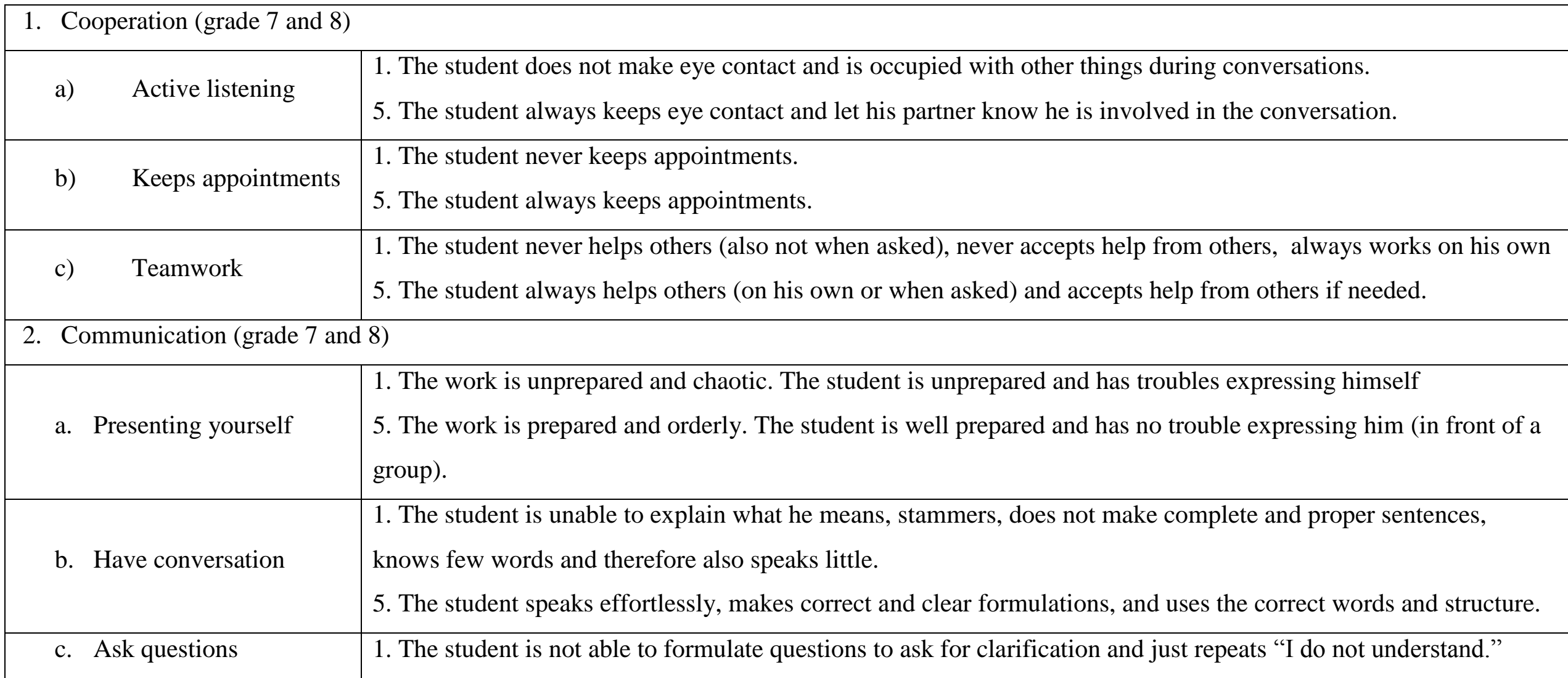




\begin{tabular}{|c|c|}
\hline & 5. The student asks the right questions at the right time. \\
\hline \multicolumn{2}{|c|}{ 3. Attitude (grade 8 only) } \\
\hline a. Independence & $\begin{array}{l}\text { 1. The student asks continuously/for each step for help to complete his assignments. } \\
\text { 5. The student completely completes the assignment on his own. }\end{array}$ \\
\hline b. Perseverance & $\begin{array}{l}\text { 1. The student does not start an assignment when he thinks he cannot succeed. } \\
\text { 5. The student will continue working on an assignment until the assignment has been successfully completed. }\end{array}$ \\
\hline c. Concentration & $\begin{array}{l}\text { 1. The student cannot concentrate during the lesson. } \\
\text { 5. The student is always very concentrated during his work. }\end{array}$ \\
\hline
\end{tabular}

